OPEN ACCESS

Edited by:

Antonella Gasbarri,

University of L'Aquila, Italy

Reviewed by:

Nadja Schroder

Universidade Federal do Rio Grande

do Sul (UFRGS), Brazil

Pietro Aricò,

Sapienza University of Rome, Italy

${ }^{*}$ Correspondence:

Yi Xiao

canghaiyisu1981@126.com

Received: 08 April 2018

Accepted: 16 January 2019

Published: 12 February 2019

Citation:

Xiao Y, Wu J, Tang W, Sun C, Ma F and Guo L (2019) Cognition Impairment Prior to Errors of Working

Memory Based on Event-Related

Potential.

Front. Behav. Neurosci. 13:13. doi: 10.3389/fnbeh.2019.00013

\section{Cognition Impairment Prior to Errors of Working Memory Based on Event-Related Potential}

\author{
Yi Xiao ${ }^{1 *}$, Jintao $W^{1,2}$, Weicai Tang ${ }^{1}$, Chenhui Sun ${ }^{1}$, Feng $\mathrm{Ma}^{1,3}$ and Lingling Guo ${ }^{1,4}$ \\ ${ }^{1}$ National Key Laboratory of Human Factors Engineering, China Astronaut Research and Training Center, Beijing, China, \\ ${ }^{2}$ School of Biological Science and Medical Engineering, Beihang University, Beijing, China, ${ }^{3}$ School of Aerospace \\ Engineering, Tsinghua University, Beijing, China, ${ }^{4}$ Department of Psychology, Zhejiang Sci-Tech University, Hangzhou, China
}

Cognitive impairment contributes to errors in different tasks. Poor attention and poor cognitive control are the two neural mechanisms for performance errors. A few studies have been conducted on the error mechanism of working memory. It is unclear whether the changes in memory updating, attention, and cognitive control can cause errors and, if so, whether they can be probed at the same time in one single task. Therefore, this study analyzed event-related potentials in a two-back working memory task. A total of 40 male participants finished the task. The differences between the error and the correct trials in amplitudes and latencies of N1, P2, N2, and P3 were analyzed. The P2 and P3 amplitudes decreased significantly in the error trials, while the N2 amplitude increased. The results showed that impaired attention, poor memory updating, and impaired cognitive control were consistently associated with the error in working memory. Furthermore, the results suggested that monitoring the neurophysiological characteristics associated with attention and cognitive control was important for studying the error mechanism and error prediction. The results also suggested that the P3 and N2 amplitudes could be used as indexes for error foreshadowing.

Keywords: attention, cognitive control, cognition impairment, memory updating, N2, P3, working memory

\section{INTRODUCTION}

Performance errors may have serious consequences. For instance, the error made by Apollo astronauts almost led to the collision of the moon with their spacecraft (Shayler, 2000). Further, a serious mistake made by a driver may lead to casualties and loss of the means of transport. Therefore, it is important to study the errors for improving human-system safety. Many causes account for errors, with some defaults in cognitive function playing an important role. Investigating the error-related neural patterns is important to uncover the error mechanisms, thus helping in improving the safety.

The error-related neural mechanisms were usually through analyzing the event-related potentials (ERPs) (Ridderinkhof et al., 2003; Hajcak et al., 2005; Padilla et al., 2006; Maidhof et al., 2009; Masaki et al., 2012; Wessel et al., 2012; Bode and Stahl, 2014; Ora et al., 2015; Shou et al., 2015). Lapse of attention (Padilla et al., 2006; Hanslmayr et al., 2007; Klimesch et al., 2007; Mathewson et al., 2009; Jensen and Mazaheri, 2010) and decreased cognitive control (Ridderinkhof et al., 2003; Kok et al., 2004; Schmajuk et al., 2006; O'Connell et al., 2009) are the two main error-related neural patterns (Mazaheri et al., 2009; Eichele et al., 2010; Shou et al., 2015). Decreased P3 amplitude in 
the centroparietal region validating the lapse of sustained attention is the cause of error (Padilla et al., 2006; Hanslmayr et al., 2007; Mathewson et al., 2009; Jensen and Mazaheri, 2010). The diminished N2 amplitude in the error trials showed that the impaired cognitive control was the reason for errors (Kok et al., 2004; Falkenstein, 2006; O'Connell et al., 2009). The $\mathrm{N} 2$ amplitude correlated with the cognitive control, reflecting the psychology template mismatch, response inhibition, and selection (Patel and Azzam, 2005; Azizian et al., 2006; Folstein and Van, 2008; Gajewski et al., 2008). Some studies indicated that an increased N2 amplitude also correlated with an impaired cognitive control (Kok, 1990; Pinal et al., 2015). A larger amplitude reflects increased energetic costs (Kok, 1990; Pinal et al., 2015), with more resources allocated and more neurons activated. Generally speaking, more efforts are needed for performing the same task with poor performance, indicating an impairment of the cognitive control.

A few studies explored the error-related neural mechanism (Ora et al., 2015; Shou et al., 2015) by analyzing multiple cognitive processes in one single task. Ora et al. (2015) analyzed the spatiotemporal neural activities during performance errors and found that attentional lapses and inappropriate action impulses caused subsequent performance errors in a $\mathrm{d} 2$ task. Shou et al. (2015) studied the error mechanism by the comprehensive analysis of N2 and alpha power in the Stroop task. The results revealed that the alpha power of error increased in the parietooccipital area under congruent trials, while the N2 amplitude decreased only in incongruent trials. These findings implied that poor sustained attention and poor cognitive control caused errors. As to working memory, what cognitive changes may cause errors is still unknown.

Memory updating is the key process of working memory. The P3 amplitude is associated with memory updating, and its latency is related to match function (Watter et al., 2001; Chen et al., 2008). On the contrary, P3 is closely linked with attention and cognitive resource reallocation. P3a is bound with attention to the selection-driven stimulus, especially the novelty stimulus (Falkenstein et al., 1994; Polich, 2007). In contrast, the P3b (Polich and Heine, 1996; Schapkin and Freude, 2013) is related to the reallocation of cognitive resources and memory. Some studies showed that a few cognitive resources were reallocated to other memory processes, resulting in a longer P3 latency and a decreased P3 amplitude (Polich, 2007; Daffner et al., 2011; Wild-Wall et al., 2011; Saliasi et al., 2013; Gajewski and Falkenstein, 2014) in working memory. One study also showed that latency jitter can decreased P3 amplitude (Aricò et al., 2014). P2 is part of memory information process related to the onset of memory updating (Lenartowicz et al., 2010; Yuan et al., 2016). N2 is regarded as an ERP component related to cognitive control in memory (Daffner et al., 2011; Gajewski and Falkenstein, 2014). N1 is the early component of information process, which remains sensitive to physical features of stimulus and reflects the recognition and code processes (Ritter et al., 1979; Hopf et al., 2002). To date, no studies have reported on the error mechanism of working memory. It is unknown whether memory updating, attention, and cognitive control may change in working memory and cause errors. No studies have identified error-related neural patterns in one single task for working memory. Therefore, the two-back working memory task was adopted in this study to investigate error-related neural patterns and cognition impairment.

A few studies showed the N1 difference in errors. Maybe, the stimulus is identical in correct and error trials. Also, it is too simple for recognition and hardly leads to error. Therefore, N1 was analyzed to verify the hypothesis in the present study. The memory updating is the key cognitive process in working memory. Therefore, the P3 and P2 amplitudes may decrease in error trials. Some studies (Ridderinkhof et al., 2003; Kok et al., 2004; Padilla et al., 2006; Schmajuk et al., 2006; Hanslmayr et al., 2007; Klimesch et al., 2007; Eichele et al., 2008; Mathewson et al., 2009; Mazaheri et al., 2009; O’Connell et al., 2009; Jensen and Mazaheri, 2010; Bode and Stahl, 2014; Ora et al., 2015; Shou et al., 2015) showed that poor attention and poor cognitive control were the error-related neural patterns, leading to changes in P3 and N2. The P2 and P3 amplitudes may decrease in error trials, but the N2 amplitude may increase for impaired cognitive control due to the energy cost theory (Kok, 1990; Pinal et al., 2015).

\section{MATERIALS AND METHODS}

\section{Participants}

This study was approved by the ethics committee of China Astronaut Research and Training Center. All participants provided written informed consent in accordance with the Declaration of Helsinki. For this study, 40 male participants, aged 19-34 years with an average age of 24 years [standard deviation $(\mathrm{SD})=2.92)$ ] were enrolled. The participants were postgraduate or graduate students with normal or corrected-tonormal vision and without any reported psychiatric disorders. Five participants were excluded because of too many artifacts in electroencephalogram (EEG), and the remaining 31 participants who had more than 20 performance errors were selected for further analysis.

\section{Two-Back Working Memory Task}

A numerical two-back task was used in the present study (Yuan et al., 2016) The sequences of $1,2,3,4,5,6,7,8$, and 9 were pseudo-randomly displayed in a white against black background on a 24-inch LCD screen (with an updating rate of $60 \mathrm{~Hz}$ ) one by one. The height and width of the stimulus were 1.8 and $1.4 \mathrm{~cm}$, respectively. At the beginning of each trial, a stimulus (Figure 1) was displayed for $500 \mathrm{~ms}$ or disappeared if responded. Then, a new stimulus was displayed after 2500 ms. Participants were required to press the "F" or "J" button as accurately and quickly as possible. If the stimulus presented was the same as the one that had appeared two presentations before, the participants were required to press the button "F"; if not, the participants were required to press the button "J." The time of the task was $10 \mathrm{~min}$, and the target rate was $33.33 \%$. The number of trials was different between participants, probably due to the reaction times. However, the minimum number was 200 from the required time in the task design. 


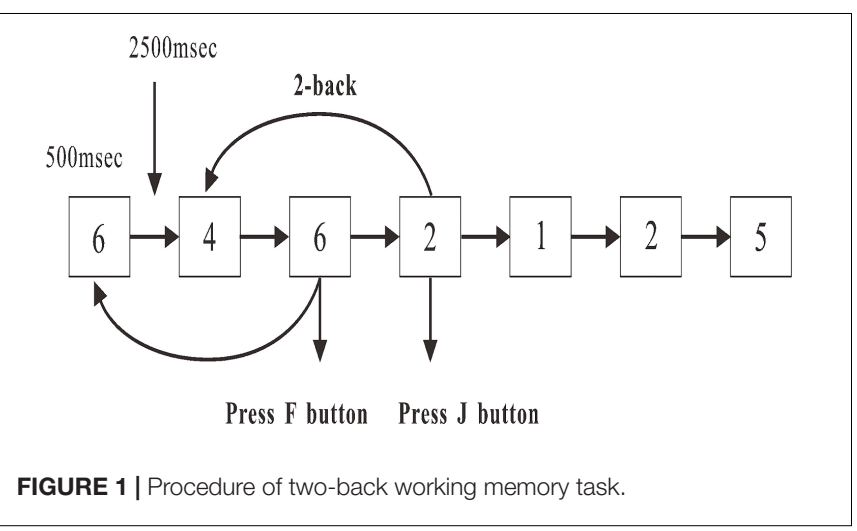

\section{Procedure}

The participants were needed to come to the laboratory two times. The first time was to get training, 1 day before the test, to ensure that all participants were familiar with the task. The second time was to get the formal test the next day. EEG data were recorded during the working memory test. The laboratory had a shield room. The participants were seated in the shield room to record the EEG data. The size of the shield room was $2.4 \mathrm{~m} \times 2.4 \mathrm{~m} \times 2.4 \mathrm{~m}$.

\section{EEG Recording}

Electroencephalogram data were recorded during the working memory test. After placement of electrodes, the participants were requested to sit in a comfortable chair $80 \mathrm{~cm}$ away from the LCD screen and instructed to refrain from excessive blinking and movement during data collection. Participants then underwent a two-back working memory task. Then, the EEG was recorded with $\mathrm{Ag}-\mathrm{AgCl}$ electrodes embedded in an elastic cap (EasyCap, Brain Products $\mathrm{GmbH}$ ) at 63 scalp locations according to the 10-20 system of Jasper (1958). The vertical electrooculogram (vEOG) was recorded from an electrode infraorbital to the left eye and the horizontal EOG was recorded at the outer canthi of the right eye. The ground electrode was positioned at AFz, and the reference electrode was positioned at FCz. The Vertical and horizontal electrooculogram (EOG) were recorded from electrodes above and below the right eye and on the outer canthi of both eyes. The electrode impedance was kept below $5 \mathrm{k} \Omega$. Signals were recorded using the BrainVision Recorder (Brain Products $\mathrm{GmbH}$, Ver. 1.03), with a band-pass filtered at $0.01-250 \mathrm{~Hz}$. The sampling rate was $1000 \mathrm{~Hz}$, and the signals were amplified in the range of $\pm 3.27 \mathrm{mV}$, and at a resolution of $0.1 \mu \mathrm{V}$.

\section{Statistical Analysis of Behavioral Data}

Descriptive statistics of error rate, reaction times (RTs) of correct and error responses, and the total number of errors were computed. The error was that the response did not accord to the stimulus. For example, although the button accorded to the stimulus was "F", the participant pressed "J"; this was an error response. The omission was not included in error statistics. The error rate was defined as the number of error responses divided by the total number of responses. RTs of two trials (correct vs. error) were examined using the paired $t$-test (Hsieh et al., 2010; Murphy et al., 2010; Sambrook and Goslin, 2014; Ora et al., 2015; Shou et al., 2015).

\section{EEG Analysis}

The EEG data were processed off-line using the BrainVision Analyzer 2.0. Software (Brain Products $\mathrm{GmbH}$, German). The mastoids (TP9, TP10) were selected as the new references (Brain Products GmbH; Möckel et al., 2015). The semi-automatic inspection method was implemented to inspect the raw data. The gradient criterion was set at $50 \mu \mathrm{V} / \mathrm{ms}$. The maximum absolute difference allowed was $200 \mu \mathrm{V}$ with a 200-ms interval. The amplitude was in the range of -200 to $200 \mu \mathrm{V}$. The allowed activity with the lowest amplitude was $0.5 \mu \mathrm{V}$. After inspecting the raw data, the EEG signals were corrected for eye movement artifacts using the artifact rejection method, which was based on the Gratton and Coles' algorithm. This procedure was implemented in the BrainVision Analyzer 2.0 Software. The continuous EEG signals were filtered using a band-pass filter from 0.1 to $35 \mathrm{~Hz}$ with a 0 -phase shift of $48 \mathrm{~dB}$, and the notch filter was $50 \mathrm{~Hz}$.

Stimulus-locked data were segmented into epochs of $-200 \mathrm{~ms}$ to $800 \mathrm{~ms}$ after stimulus and were baseline-corrected relative to the interval of $-200 \mathrm{~ms}$ to $0 \mathrm{~ms}$. The ERPs of accepted trials were then averaged separately for obtaining a correct or error trial. The N1, P2, N2, and P3 values were quantified as the maximum amplitudes, and the intervals were increased from 130 to $170 \mathrm{~ms}, 170$ to $270 \mathrm{~ms}, 270$ to $360 \mathrm{~ms}$, and 400 to $500 \mathrm{~ms}$ post-stimulus, respectively. The maximum amplitudes of each ERP component were the average of 10 points around the peak amplitude. Grand average waveforms of N1, N2, and P3 were created for the correct and error trials at each of the three electrode sites $(\mathrm{Fz}, \mathrm{Cz}$, and $\mathrm{Pz})$. The three components were analyzed using a two-way repeatedmeasures analysis of variance with Trial (correct and error) and Site $(\mathrm{Fz}, \mathrm{Cz}$, and $\mathrm{Pz})$ as within-subject factors (Gehring and Fencsik, 2001). With no overt P2 in Pz, ANOVA with repeated measures was conducted on $\mathrm{P} 2$ with Trial (correct and error) and Site $(\mathrm{Fz}$ and $\mathrm{Cz})$ as within-subject variables. The partial eta squared $\left(\eta_{\mathrm{p}}^{2}\right)$ was the effect size, and the GreenhouseGeisser correction was used where appropriate (Liu et al., 2015). Paired-sample $t$-tests were used for analysis of latencies of Trial (correct and error).

\section{RESULTS}

\section{Behavioral Results}

Due to different RTs, the response number of the participants was between 200 and 422 within $10 \mathrm{~min}$ and the mean response number was $356.4(\mathrm{SD}=59.8)$. The mean error rate was 0.12 $(\mathrm{SD}=0.05)$ with the $0.01(\mathrm{SD}=0.02)$ omission rate, and the mean error responses in 31 participants was $43.8(\mathrm{SD}=18.6)$. The RTs of error trials were significantly longer than those of correct trials $(t=-2.078 ; P=0.01)$. The results are shown in Figure 2. 


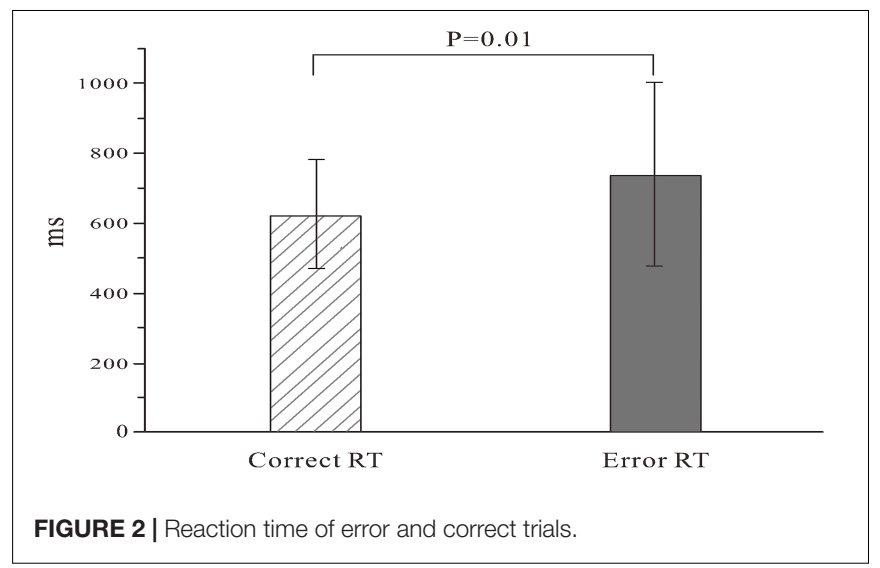

\section{ERP Results}

The means of ERP amplitudes and latencies are shown in Tables 1, 2. The ERP wave and mapping of correct and error trials of all participants are presented in Figures 3, 4 .

For the N1 amplitudes, no main effect of trial was observed $\left[F(1,30)=0.386 ; P=0.539 ; \eta_{\mathrm{p}}^{2}=0.013\right]$, but a main effect of electrode sites was found $[F(1.207,36.207)=8.260$; $\left.\left.P=0.004 ; \eta_{\mathrm{p}}^{2}=0.216\right)\right]$ and the $\mathrm{Fz}$ showed the largest amplitude. In contrast, the $\mathrm{Pz}$ amplitude was the smallest. However, no interaction effect was noted between electrode sites and trials $[F(1.385,41.546)=0.141 ; \quad P=0.790$; $\left.\eta_{\mathrm{p}}^{2}=0.005\right]$.

The P2 amplitudes decreased in error trials significantly $\left[F(1,30)=4.211 ; P=0.049 ; \eta_{\mathrm{p}}^{2}=0.123\right]$. Moreover, a main effect of electrode sites was observed $[F(1,30)=4.506 ; P=0.042$; $\left.\eta_{\mathrm{p}}^{2}=0.131\right]$. The $\mathrm{Fz}$ amplitude was the largest, but the $\mathrm{Cz}$ amplitude was the smallest. However, no significant interaction effect was observed between the electrode sites and the trials $\left[F(1,30)=2.244 ; P=0.145 ; \eta_{\mathrm{p}}^{2}=0.070\right]$.

For the N2 amplitudes, the amplitude in the error trial increased significantly $[F(1,30)=5.142 ; \quad P=0.031$; $\left.\eta_{\mathrm{p}}^{2}=0.146\right]$. However, no main effect of electrode sites was found $\left[F(1.185,35.551)=0.290 ; P=0.632 ; \eta_{\mathrm{p}}^{2}=0.010\right]$. Additionally, no interaction effect was observed between electrode sites and trials $\left[F(1.076,32.392)=0.533 ; P=0.483 ; \eta_{\mathrm{p}}^{2}=0.017\right]$.

For the P3 amplitudes, the amplitudes of error trial decreased significantly $\left[F(1,30)=6.663 ; P=0.015 ; \eta_{\mathrm{p}}^{2}=0.182\right]$. Furthermore, a main effect of electrode sites was noted $\left[F(1.240,37.191)=10.607 ; P=0.001 ; \eta_{\mathrm{p}}^{2}=0.261\right]$. The Pz $(\mathrm{P} 3 \mathrm{~b})$ amplitude was the largest, but the $\mathrm{Fz}$ (P3a) amplitude was the smallest. However, no significant interaction effects were found between the electrode sites and the trials $[F(1.335,40.047)=0.660$; $\left.P=0.464 ; \eta_{\mathrm{p}}^{2}=0.022\right]$. The mean amplitudes of all participants (Figure 3) showed that the amplitudes in correct trial were far larger than the errors, especially in the central and parietal areas. These results were also illustrated using topographic maps (Figure 4).

The $t$-test of latency in different trials (correct vs. error) for N1, $\mathrm{N} 2, \mathrm{P} 2$, and $\mathrm{P} 3$ revealed no significant difference (N1: $t=1.40$, $P=0.17 ; \mathrm{N} 2: t=0.82, P=0.42 ; \mathrm{P} 2: t=-0.24, P=0.81$; P3: $t=-0.67, P=0.51)$.

\section{DISCUSSION}

The present study partially verified the hypotheses. Reduced P2 and P3 amplitudes in error trials were found. However, the N2 amplitudes increased in error trials. The RT of the error trial was longer than that of the correct trial. The results revealed that poor attention, poor cognitive control, and impaired memory

TABLE 1 | Event-related potential amplitudes.

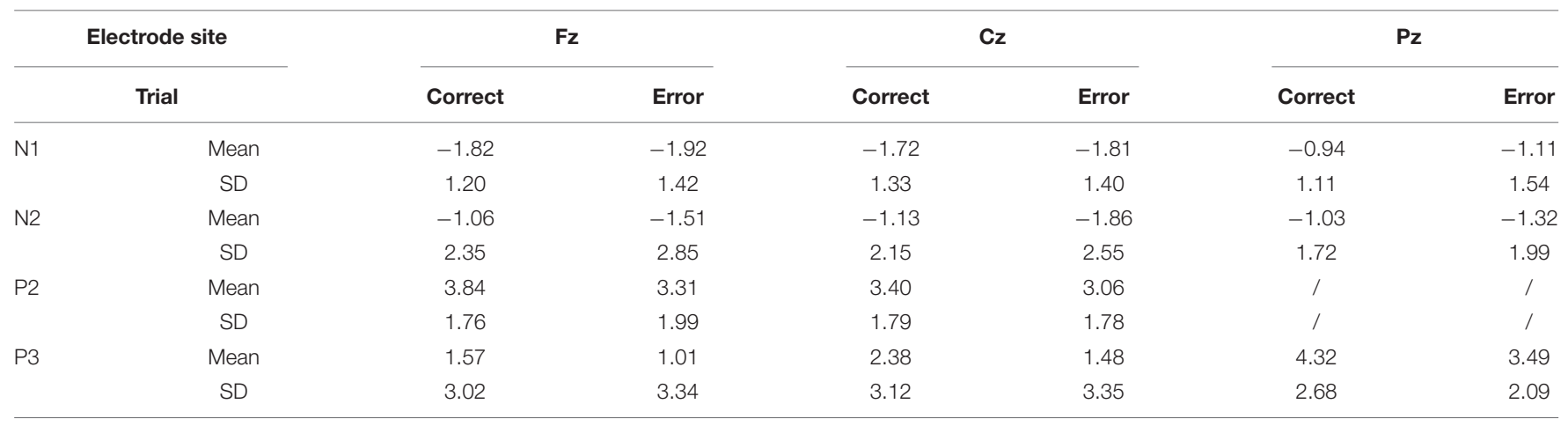

TABLE 2 | Event-related potential latency.

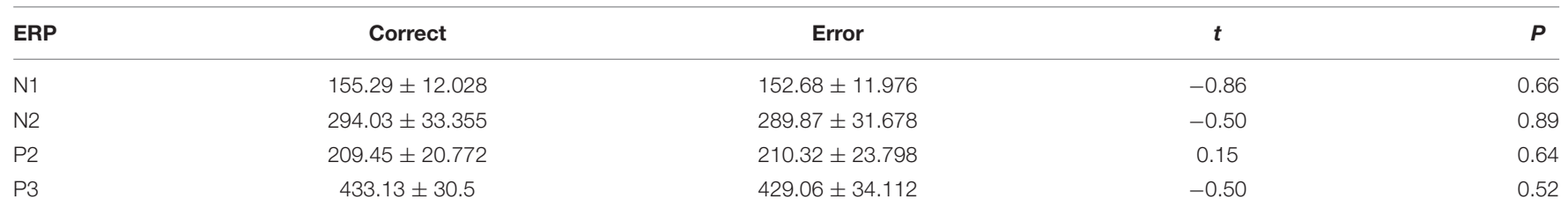




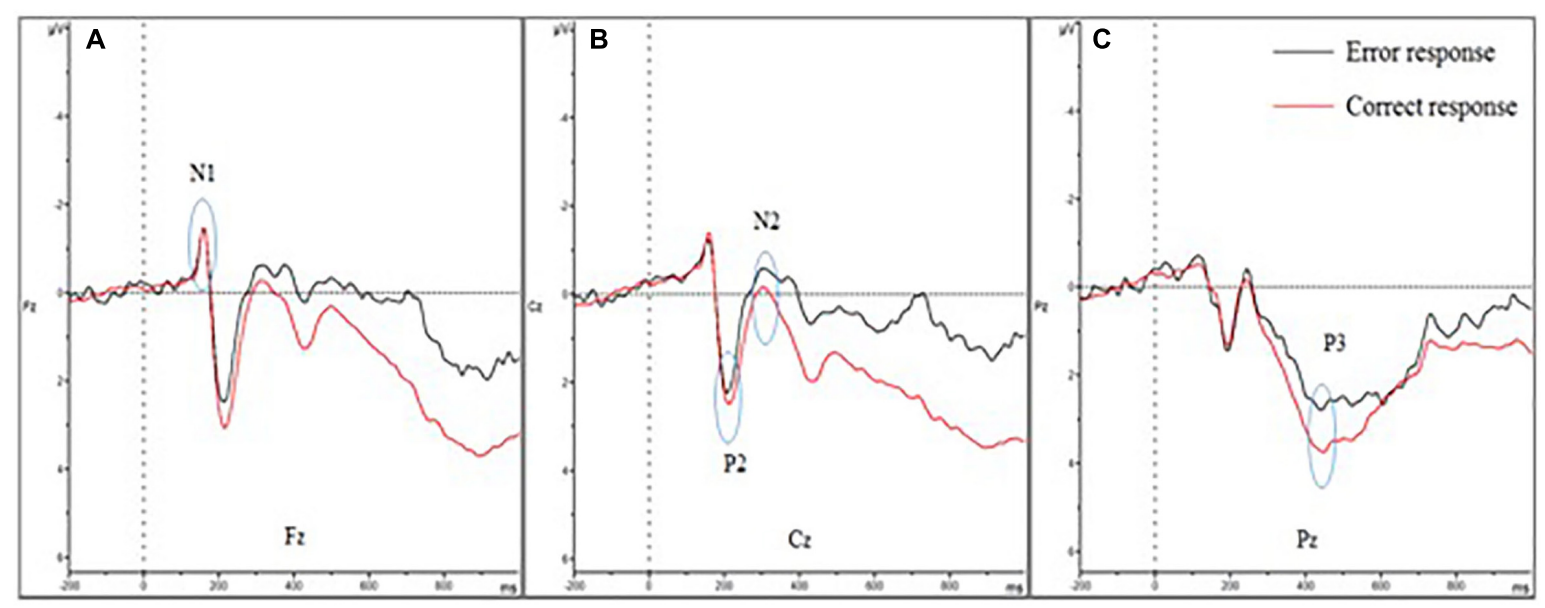

FIGURE 3 | Event-related potential of correct and error trials of all participants. (A-C) show the N1, P2, N2, and P3 amplitudes of the two trials. (A) Shows the four amplitudes in Fz; (B) shows the four amplitudes in Cz; and (C) shows the four amplitudes in Pz. The N1 amplitude showed no difference between error and correct trials. The P2 and P3 amplitudes diminished in error trials, while the N2 amplitude was larger.

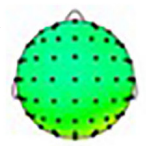

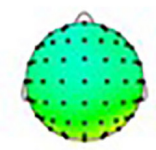
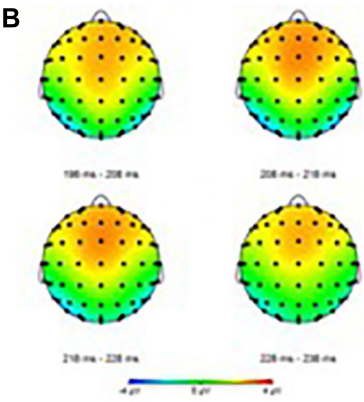

E
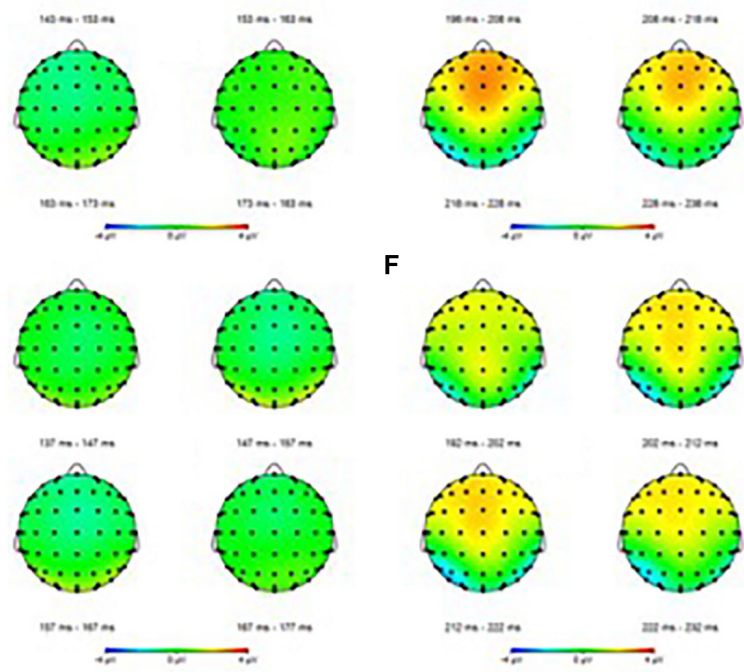

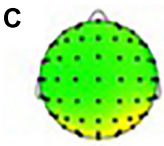

C

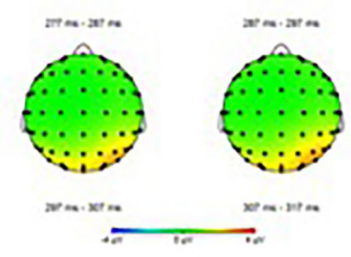

G
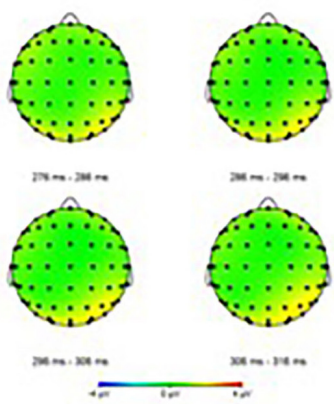

D
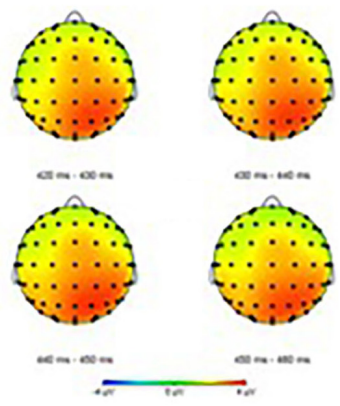

H
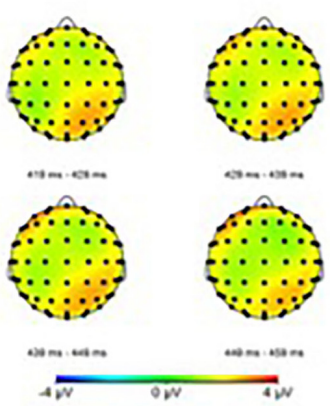

FIGURE 4 | Event-related potential mapping of correct and error trials. (A-D) Show the N1, P2, N2, and P3 mapping of correct ERP, respectively; (E-G) show the N1, P2, N2, and P3 mapping of error ERP, respectively. (A,E) Show the N1 amplitudes of the two trials; (B,F) show that the P2 amplitudes of the error trials was smaller than that of the correct trials in central areas; $(\mathbf{C}, \mathbf{G})$ show the N2 amplitudes of the two trials; $(\mathbf{D}, \mathbf{H})$ show that the P3 amplitudes of the error trials was smaller than that of the correct trials in the parietal areas.

updating might cause errors in working memory. The N1 amplitudes showed no difference between the two trials.

As expected, the $\mathrm{N} 1$ amplitudes showed no significant changes in different trials. N1 is thought to be the early component of information processing. Its amplitudes reflect the recognition and code processing of stimulus (Kutas and Hillyard, 1980; Hopf et al., 2002), which are sensitive to the physical features of the stimulus. Therefore, the results indicated that the neural activity was comparable during the stimulus encoding stage of working memory process between correct and error trials. Additionally, no differences were found between trials that resulted from the same too simple physical features of the stimulus.

No study has been found regarding the association of P2 with an error. The results revealed that the P2 amplitude decreased when participants presented an error response. Previous studies found that the P2 component reflected the 
initial stage of context updating, and was believed to be the onset of memory updating (Lenartowicz et al., 2010; Yuan et al., 2016). Therefore, the diminished amplitudes of error trials were related to the impaired ability of memory updating onset. The onset of updating was encoded after stimuli and then translated to phonological representations. Thus, it was considered one of the crucial steps for successful performance and impaired ability, resulting in an error response in this study.

The increased N2 amplitude in error trial implied that the cognitive control decreased (Kok, 1990; Caseras et al., 2006; Unsworth et al., 2009; Bode and Stahl, 2014; Pinal et al., 2015) and induced errors based on the energy cost theory (Kok, 1990; Pinal et al., 2015). N2 was related to cognitive control, including response selection and conflict detection in memory (Daffner et al., 2011; Gajewski and Falkenstein, 2014). The peak N2 amplitude was significantly larger in the older group than in the younger group (Pinal et al., 2015), which might be due to the use of more energy for the older participants. The increased N2 amplitude reflected an enhanced energetic cost in cognitive control, such as mismatch and response selection (Nieuwenhuis et al., 2005; Folstein and Van, 2008; Daffner et al., 2011; O'connell et al., 2012b). Previous studies showed that a high N2 amplitude was found in patients than in controls because the patients need more resources to process the information including the mismatch and response selection (Bruder et al., 1998, 2001; Daurignac et al., 2006; Guillem et al., 2006; Shu et al., 2014; Sumich et al., 2014; Pinal et al., 2015; Zuj et al., 2017). A larger N2 amplitude possibly demanded greater efforts in task completion and even induced hyperactivation by way of more efforts during the completion of a relatively simple task (Bruder et al., 1998, 2001; Guillem et al., 2006; Sumich et al., 2014). Some studies showed a diminished P3 amplitude in working memory because more resources were recruited in the cognitive control and increased the N2 amplitude (Daffner et al., 2011; Gajewski and Falkenstein, 2014). More neuron-related cognitive control was activated, subsequently increasing the $\mathrm{N} 2$ amplitude. The stimulus was identical in all the error and correct trials, and therefore the cognitive demands remained the same. This indicated that more resources were used for the same task, and the error rate increased, indicating a declination in cognitive ability in the wrong trial.

P3 was associated with sustained attention, cognitive resource reallocation (Snyder and Hillyard, 1976; Donchin, 1981; Nieuwenhuis et al., 2005; Polich and Criado, 2006; Polich, 2007; Verleger, 2008; Duncan et al., 2009; Beste et al., 2010; Hart et al., 2012; O'Connell et al., 2012a; Kim and Kim, 2016), and memory updating (Donchin and Coles, 1988; Polich, 2007; Zhao et al., 2013).

\section{Decreased P3 Amplitude Reflected Impaired Attention}

Falkenstein and Polich (Falkenstein et al., 1994; Polich, 2007) showed that frontal P3(P3a) was related to attention selection (Polich and Heine, 1996; Schapkin and Freude, 2013) and parietal
P3(P3b) was associated with cognitive resource reallocation. The decreased P3 amplitude in frontal and parietal areas implied that some resources were reallocated in other memory processes, impairing the attention. Gajewski and Falkenstein (2014) found that cognitive resource was reallocated in other processes and the impaired attention led to a decreased P3 amplitude in the two-back working memory task (Polich and Heine, 1996; Polich, 2007; Daffner et al., 2011; Wild-Wall et al., 2011; Saliasi et al., 2013; Schapkin and Freude, 2013). A decline of P3 amplitude in frontal and parietal areas implied impaired attention and diminished cognitive resources, resulting in increased omission rate, false alarm, and more errors (Donchin and Coles, 1988; Polich, 2007; Zhao et al., 2013; Schapkin and Freude, 2014). On the contrary, longer RT in error trials was thought as attention lapses, which was supported by fMRI (Weissman et al., 2006) and other findings (Padilla et al., 2006). This was consistent with the results of the present study, which implied impaired attention.

\section{Decreased P3 Amplitude Reflected Deficit Ability in Memory Updating}

The P3 amplitude is an effective measurement of memory updating (Donchin and Coles, 1988; Watter et al., 2001; Polich, 2007; Chen et al., 2008; Zhao et al., 2013), and the latency is related to the match function (Donchin and Coles, 1988; Watter et al., 2001; Polich, 2007; Chen et al., 2008; Zhao et al., 2013). The ability associated with memory updating increased with better performance, leading to an increased P3 amplitude in the parietal area when the participants underwent n-back training (Watter et al., 2001; Chen et al., 2008). A reduced amplitude indicated that the memory updating capability was impaired. Updating included code, operation, search, and selection of information. Impaired memory updating caused some faults in information operation and updating in the memory mode. Thus, the errors were related with poor memory updating.

\section{CONCLUSION}

Diminished P3 and P2 amplitudes and an increased N2 amplitude in errors were related to impaired attention and deficit in memory updating and cognitive control. The diminished P3 amplitude indicated that more cognitive resources were reallocated to other memory processes, leading to impaired attention in the memory updating process. As a result, it caused a deficit in the ability of memory updating and decreased cognitive control. This was the first study on the poor memory updating causing errors.

Poor attention and cognitive control were the major causes of error in many common tasks (Ridderinkhof et al., 2003; Kok et al., 2004; Padilla et al., 2006; Schmajuk et al., 2006; Hanslmayr et al., 2007; Klimesch et al., 2007; Mathewson et al., 2009; O'Connell et al., 2009; Jensen and Mazaheri, 2010). Hence, much attention should be paid to the neurocognitive characteristics, which are important for error mechanism and can be used as indexes for error prediction. How to predict the error based on EEG trial-totrial analysis needs further investigation in the future. 


\section{AUTHOR CONTRIBUTIONS}

All authors listed have made a substantial, direct and intellectual contribution to the work, and approved it for publication.

\section{FUNDING}

This study was supported by the National Natural Science Foundation of China (71201148), the Foundation of National Key Laboratory of Human Factors Engineering (Grant

\section{REFERENCES}

Aricò, P., Aloise, F., Schettini, F., Salinari, S., Mattia, D., and Cincotti, F. (2014). Influence of p300 latency jitter on event related potential-based braincomputer interface performance. J. Neural Eng. 11:035008. doi: 10.1088/17412560/11/3/035008

Azizian, A., Freitas, A. L., Parvaz, M. A., and Squires, N. K. (2006) Beware misleading cues: perceptual similarity modulates the N2/P3 complex. Psychophysiology 43, 253-260. doi: 10.1111/j.1469-8986.2006.00409.x

Beste, C., Willemssen, R., Saft, C., and Falkenstein, M. (2010). Response inhibition subprocesses and dopaminergic pathways: basal ganglia disease effects. Neuropsychologia 48, 366-373. doi: 10.1016/j.neuropsychologia.2009. 09.023

Bode, S., and Stahl, J. (2014). Predicting errors from patterns of event-related potentials preceding an overt response. Biol. Psychol. 103, 357-369. doi: 10. 1016/j.biopsycho.2014.10.002

Bruder, G. E., Kayser, J., Tenke, C. E., Friedman, M., Malaspina, D., and Gorman, J. M. (2001). Event-related potentials in schizophrenia during tonal and phonetic oddball tasks: relations to diagnostic subtype, symptom features and verbal memory. Biol. Psychiatry 50, 447-452. doi: 10.1016/S0006-3223(01) 01168-4

Bruder, G. E., Tenke, C. E., Towey, J. P., Leite, P., Fong, R., Stewart, J. E., et al. (1998). Brain ERPs of depressed patients to complex tones in an oddball task: relation of reduced P3 asymmetry to physical anhedonia. Psychophysiology 35, 54-63. doi: 10.1111/1469-8986.3510054

Caseras, X., Mataix-Cols, D., Giampietro, V., Rimes, K. A., Brammer, M., Zelaya, F., et al. (2006). Probing the working memory system in chronic fatigue syndrome: a functional magnetic resonance imaging study using the n-back task. Psychosom. Med. 68, 947-955. doi: 10.1097/01.psy.0000242770.50979.5f

Chen, Y.-N., Mitra, S., and Schlaghecken, F. (2008). Sub-processes of working memory in the N-back task: an investigation using ERPs. Clin. Neurophysiol. 119, 1546-1559. doi: 10.1016/j.clinph.2008.03.003

Daffner, K. R., Chong, H., Sun, X., Tarbi, E. C., Riis, J. L., McGinnis, S. M., et al. (2011). Mechanisms underlying age-and performance-related differences in working memory. J. Cogn. Neurosci. 23, 1298-1314. doi: 10.1162/jocn.2010. 21540

Daurignac, E., Houdé, O., and Jouvent, R. (2006). Negative priming in a numerical Piaget-like task as evidenced by ERP. J. Cogn. Neurosci. 18, 730-736. doi: 10. 1162/jocn.2006.18.5.730

Donchin, E. (1981). Surprise!... surprise? Psychophysiology 18, 493-513. doi: 10. 1111/j.1469-8986.1981.tb01815.x

Donchin, E., and Coles, M. G. (1988). Is the P300 component a manifestation of context updating? Behav. Brain Sci. 11, 357-374. doi: 10.1016/j.clinph.2009. 07.045

Duncan, C. C., Barry, R. J., Connolly, J. F., Fischer, C., Michie, P. T., Näätänen, R., et al. (2009). Event-related potentials in clinical research: guidelines for eliciting, recording, and quantifying mismatch negativity. P300, and N400. Clin. Neurophysiol. 120, 1883-1908. doi: 10.1016/j.clinph.2009.07.045

Eichele, H., Juvodden, H. T., Ullsperger, M., and Eichele, T. (2010). Mal-adaptation of event-related EEG responses preceding performance errors. Front. Hum. Neurosci. 4:65. doi: 10.3389/fnhum.2010.00065

Eichele, T., Debener, S., Calhoun, V. D., Specht, K., Engel, A. K., Hugdahl, K., et al. (2008). Prediction of human errors by maladaptive changes in event-related
Nos. SYFD160051807, HF2017-Z-Z-A-01, HF2011-Z-B-02, HF2011-Z-Z-B-02, HF2012-Z-B-02, SYFD180051801, and 6142222180204), and the Equipment Advanced Research Project (No. 51326050204).

\section{ACKNOWLEDGMENTS}

The authors would like to thank Jianhui WU, Professor of Psychology, Shenzhen University, for his advice on ERP data analysis.

brain networks. Proc. Natl. Acad. Sci. U.S.A. 105, 6173-6178. doi: 10.1016/j. neuropsychologia.2006.12.014

Falkenstein, M. (2006). Inhibition, conflict and the Nogo-N2. Clin. Neurophysiol. Off. J. Int. Fed. Clin. Neurophysiol. 117, 1638-1640.

Falkenstein, M., Hohnsbein, J., and Hoormann, J. (1994). Effects of choice complexity on different subcomponents of the late positive complex of the event-related potential. Electroencephalogr. Clin. Neurophysiol. 92, $148-160$.

Folstein, J. R., and Van, P. C. (2008). Influence of cognitive control and mismatch on the N2 component of the ERP: a review. Psychophysiology 45, 152-170. doi: $10.1027 / 0269-8803 / \mathrm{a} 000123$

Gajewski, P. D., and Falkenstein, M. (2014). Age-related effects on ERP and oscillatory EEG-dynamics in a 2-back task. J. Psychophysiol. 28, 162-177. doi: 10.1016/j.brainres.2007.10.076

Gajewski, P. D., Stoerig, P., and Falkenstein, M. (2008). ERP-correlates of response selection in a response conflict paradigm. Brain Res. 1189, 127-134. doi: 10. 1016/j.pnpbp.2006.02.009

Gehring, W. J., and Fencsik, D. E. (2001). Functions of the medial frontal cortex in the processing of conflict and errors. J. Neurosci. 21, 9430-9437. doi: 10.1523/ JNEUROSCI.21-23-09430.2001

Guillem, F., Chouinard, S., Poulin, J., Godbout, R., Lalonde, P., Melun, P., et al. (2006). Are cholinergic enhancers beneficial for memory in schizophrenia? An event-related potentials (ERPs) study of rivastigmine add-on therapy in a crossover trial. Prog. Neuro Psychopharmacol. Biol. Psychiatry 30, 934-945.

Hajcak, G., Nieuwenhuis, S., Ridderinkhof, K. R., and Simons, R. F. (2005). Error-preceding brain activity: robustness, temporal dynamics, and boundary trails. Biol. Psychol. 70, 67-78. doi: 10.1016/j.biopsycho.2004. 12.001

Hanslmayr, S., Aslan, A., Staudigl, T., Klimesch, W., Herrmann, C. S., and Bäuml, K. H. (2007). Prestimulus oscillations predict visual perception performance between and within subjects. Neuroimage 37, 1465-1473. doi: 10.1016/j. neuroimage.2007.07.011

Hart, E., Dumas, E., Reijntjes, R., van der Hiele, K., van den Bogaard, S., Middelkoop, H., et al. (2012). Deficient sustained attention to response task and P300 characteristics in early Huntington's disease. J. Neurol. 259, 1191-1198. doi: 10.1007/s00415-011-6334-0

Hopf, J.-M., Vogel, E., Woodman, G., Heinze, H.-J., and Luck, S. J. (2002). Localizing visual discrimination processes in time and space. J. Neurophysiol. 88, 2088-2095. doi: 10.1152/jn.2002.88.4.2088

Hsieh, S., Tsai, C. Y., and Tsai, L. L. (2010). Error correction maintains post-error adjustments after one night of total sleep deprivation. J. Sleep Res. 18, 159-166. doi: 10.1111/j.1365-2869.2008.00730.x

Jasper, H. H. (1958). The ten-twenty electrode system of the International Federation. Electroencephalogr. Clin. Neurophysiol. 10, 370-375. doi: 10.1097/ 00006534-195205000-00008

Jensen, O., and Mazaheri, A. (2010). Shaping functional architecture by oscillatory alpha activity: gating by inhibition. Front. Hum. Neurosci. 4:186. doi: 10.3389/ fnhum.2010.00186

Kim, S., and Kim, M.-S. (2016). Deficits in verbal working memory among college students with attention-deficit/hyperactivity disorder traits: an event-related potential study. Clin. Psychopharmacol. Neurosci. 14, 64-73. doi: 10.9758/cpn. 2016.14.1.64 
Klimesch, W., Sauseng, P., and Hanslmayr, S. (2007). EEG alpha oscillations: the inhibition-timing hypothesis. Brain Res. Rev. 53, 63-88. doi: 10.1016/j. brainresrev.2006.06.003

Kok, A. (1990). Internal and external control: a two-factor model of amplitude change of event-related potentials. Acta Psychol. 74, 203-236. doi: 10.1016/ 0001-6918(90)90006-2

Kok, A., Ramautar, J. R., De Ruiter, M. B., Band, G. P., and Ridderinkhof, K. R. (2004). ERP components associated with successful and unsuccessful stopping in a stop-signal task. Psychophysiology 41, 9-20. doi: 10.1046/j.1469-8986.2003. 00127.x

Kutas, M., and Hillyard, S. A. (1980). Event-related brain potentials to semantically inappropriate and surprisingly large words. Biol. Psychol. 11, 99-116. doi: 10. 1016/0301-0511(80)90046-0

Lenartowicz, A., Escobedoquiroz, R., and Cohen, J. D. (2010). Updating of context in working memory: an event-related potential study. Cogn. Affect. Behav. Neurosci. 10, 298-315. doi: 10.3758/s13415-015-0335-x

Liu, Q., Zhou, R., Liu, L., and Zhao, X. (2015). Effects of 72 hours total sleep deprivation on male astronauts' executive functions and emotion. Compr. Psychiatry 61, 28-35. doi: 10.1016/j.comppsych.2015.05.015

Maidhof, C., Rieger, M., Prinz, W., and Koelsch, S. (2009). Nobody is perfect: ERP effects prior to performance errors in musicians indicate fast monitoring processes. PLoS One 4:e5032. doi: 10.1371/journal.pone.0005032

Masaki, H., Murphy, T. I., Kamijo, K., Yamazaki, K., and Sommer, W. (2012). Foreshadowing of performance accuracy by event-related potentials: evidence from a minimal-conflict task. PLoS One 7:e38006. doi: 10.1371/journal.pone. 0038006

Mathewson, K. E., Gratton, G., Fabiani, M., Beck, D. M., and Ro, T. (2009). To see or not to see: pre-stimulus alpha phase predicts visual awareness. J. Neurosci. Off. J. Soc. Neurosci. 29, 2725-2732. doi: 10.1523/JNEUROSCI.3963-08.2009

Mazaheri, A., Nieuwenhuis, I. L., van Dijk, H., and Jensen, O. (2009). Prestimulus alpha and mu activity predicts failure to inhibit motor responses. Hum. Brain Mapp. 30, 1791-1800. doi: 10.1002/hbm.20763

Möckel, T., Beste, C., and Wascher, E. (2015). The effects of time on task in response selection - an ERP study of mental fatigue. Sci. Rep. 5:10113. doi: 10.1038/srep10113

Murphy, T. I., Richard, M., Masaki, H., and Segalowitz, S. J. (2010). The effect of sleepiness on performance monitoring: I know what I am doing, but do I care? J. Sleep Res. 15, 15-21. doi: 10.1111/j.1365-2869.2006.00503.x

Nieuwenhuis, S., Aston-Jones, G., and Cohen, J. D. (2005). Decision making, the P3, and the locus coeruleus-norepinephrine system. Psychol. Bull. 131, 510-532. doi: 10.1037/0033-2909.131.4.510

O’Connell, R. G., Balsters, J. H., Kilcullen, S. M., Campbell, W., Bokde, A. W., Lai, R., et al. (2012a). A simultaneous ERP/fMRI investigation of the P300 aging effect. Neurobiol. Aging 33, 2448-2461. doi: 10.1016/j.neurobiolaging.2011. 12.021

O'Connell, R. G., Dockree, P. M., Bellgrove, M., Turin, A., Ward, S., Foxe, J., et al. (2009). Two types of action error: electrophysiological evidence for separable inhibitory and sustained attention neural mechanisms producing error on go/no-go tasks. J. Cogn. Neurosci. 21, 93-104. doi: 10.1162/jocn.2009.21008

O'connell, R. G., Dockree, P. M., and Kelly, S. P. (2012b). A supramodal accumulation-to-bound signal that determines perceptual decisions in humans. Nat. Neurosci. 15, 1729-1735. doi: 10.1038/nn.3248

Ora, H., Sekiguchi, T., and Miyake, Y. (2015). Dynamic scalp topography reveals neural signs just before performance errors. Sci. Rep. 5:12503. doi: 10.1038/ srep12503

Padilla, M., Wood, R., Hale, L., and Knight, R. (2006). Lapses in a prefrontalextrastriate preparatory attention network predict mistakes. J. Cogn. Neurosci. 18, 1477-1487. doi: 10.1162/jocn.2006.18.9.1477

Patel, S. H., and Azzam, P. N. (2005). Characterization of N200 and P300: selected studies of the event-related potential. Int. J. Med. Sci. 2, 147-154. doi: 10.7150/ ijms.2.147

Pinal, D., Zurrón, M., and Díaz, F. (2015). Age-related changes in brain activity are specific for high order cognitive processes during successful encoding of information in working memory. Front. Aging Neurosci. 7:75. doi: 10.3389/ fnagi.2015.00075

Polich, J. (2007). Updating P300: an integrative theory of P3a and P3b. Clin. Neurophysiol. 118, 2128-2148. doi: 10.1016/j.clinph.2007.04.019
Polich, J., and Criado, J. R. (2006). Neuropsychology and neuropharmacology of P3a and P3b. Int. J. Psychophysiol. 60, 172-185. doi: 10.1016/j.ijpsycho.2005. 12.012

Polich, J., and Heine, M. R. (1996). P300 topography and modality effects from a single-stimulus paradigm. Psychophysiology 33, 747-752. doi: 10.1111/j.14698986.1996.tb02371.x

Ridderinkhof, K. R., Nieuwenhuis, S., and Bashore, T. R. (2003). Errors are foreshadowed in brain potentials associated with action monitoring in cingulate cortex in humans. Neurosci. Lett. 348, 1-4. doi: 10.1016/S0304-3940(03) 00566-4

Ritter, W., Simson, R., Vaughan, H. G., and Friedman, D. (1979). A brain event related to the making of a sensory discrimination. Science 203, 1358-1361. doi: $10.1126 /$ science. 424760

Saliasi, E., Geerligs, L., Lorist, M. M., and Maurits, N. M. (2013). The relationship between P3 amplitude and working memory performance differs in young and older adults. PLoS One 8:e63701. doi: 10.1371/journal.pone. 0063701

Sambrook, T. D., and Goslin, J. (2014). Mediofrontal event-related potentials in response to positive, negative and unsigned prediction errors. Neuropsychologia 61, 1-10. doi: 10.1016/j.neuropsychologia.2014.06.004

Schapkin, S. A., and Freude, G. (2013). Cardiovascular costs of working memory performance: effects of age and performance feedback. Ind. Health 51, 386-397. doi: 10.2486/indhealth.2012-0203

Schapkin, S. A., and Freude, G. (2014). "Neuronal mechanisms of working memory performance in younger and older employees," in Proceedings of the International Conference on Engineering Psychology and Cognitive Ergonomics, (Berlin: Springer), 70-81. doi: 10.1007/978-3-319-075 15-0_8

Schmajuk, M., Liotti, M., Busse, L., and Woldorff, M. G. (2006). Electrophysiological activity underlying inhibitory control processes in normal adults. Neuropsychologia 44, 384-395. doi: 10.1016/j.neuropsychologia. 2005.06.005

Shayler, D. (2000). Disasters and Accidents in Manned Spaceflight. Berlin: Springer. Shou, G., Dasari, D., and Ding, L. (2015). Pre-stimulus alpha and post-stimulus N2 foreshadow imminent errors in a single task. Neuropsychologia 77, 346-358. doi: 10.1016/j.neuropsychologia.2015.09.006

Shu, I.-W., Onton, J. A., Prabhakar, N., O'Connell, R. M., Simmons, A. N., and Matthews, S. C. (2014). Combat veterans with PTSD after mild TBI exhibit greater ERPs from posterior-medial cortical areas while appraising facial features. J. Affect. Disord. 155, 234-240. doi: 10.1016/j.jad.2013. 06.057

Snyder, E., and Hillyard, S. A. (1976). Long-latency evoked potentials to irrelevant, deviant stimuli. Behav. Biol. 16, 319-331. doi: 10.1016/S0091-6773(76) 91447-4

Sumich, A., Castro, A., and Kumari, V. (2014). N100 and N200, but not P300, amplitudes predict paranoia/suspiciousness in the general population. Pers. Individ. Differ. 61, 74-79. doi: 10.1016/j.paid.2014. 06301.009

Unsworth, N., Redick, T. S., Heitz, R. P., Broadway, J. M., and Engle, R. W. (2009). Complex working memory span tasks and higher-order cognition: a latentvariable analysis of the relationship between processing and storage. Memory 17, 635-654. doi: 10.1080/09658210902998047

Verleger, R. (2008). P3b: towards some decision about memory. Clin. Neurophysiol. 119, 968-970. doi: 10.1016/j.clinph.2007.11.175

Watter, S., Geffen, G. M., and Geffen, L. B. (2001). The n-back as a dual-task: P300 morphology under divided attention. Psychophysiology 38, 998-1003. doi: 10.1111/1469-8986.3860998

Weissman, D. H., Roberts, K. C., Visscher, K. M., and Woldorff, M. G. (2006). The neural bases of momentary lapses in attention. Nat. Neurosci. 9, 971-978. doi: $10.1038 / \mathrm{nn} 1727$

Wessel, J. R., Danielmeier, C., Morton, J. B., and Ullsperger, M. (2012). Surprise and error: common neuronal architecture for the processing of errors and novelty. J. Neurosci. Off. J. Soc. Neurosci. 32, 7528-7537. doi: 10.1523/JNEUROSCI. 6352-11.2012

Wild-Wall, N., Falkenstein, M., and Gajewski, P. D. (2011). Age-related differences in working memory performance in A 2-back task. Front. Psychol. 2:186. doi: 10.3389/fpsyg.2011.00186 
Yuan, Y., Leung, A. W., Duan, H., Zhang, L., Zhang, K., Wu, J., et al. (2016). The effects of long-term stress on neural dynamics of working memory processing: an investigation using ERP. Sci. Rep. 6:23217. doi: 10.1038/srep23217

Zhao, X., Zhou, R., and Fu, L. (2013). Working memory updating function training influenced brain activity. PLoS One 8:e71063. doi: 10.1371/journal. pone.0071063

Zuj, D. V., Felmingham, K. L., Palmer, M. A., Lawrence-Wood, E., Van Hooff, M., Lawrence, A. J., et al. (2017). Neural activity and emotional processing following military deployment: effects of mild traumatic brain injury and posttraumatic stress disorder. Brain Cogn. 118, 19-26. doi: 10.1016/j.bandc.2017. 07.001
Conflict of Interest Statement: The authors declare that the research was conducted in the absence of any commercial or financial relationships that could be construed as a potential conflict of interest.

Copyright (c) 2019 Xiao, Wu, Tang, Sun, Ma and Guo. This is an open-access article distributed under the terms of the Creative Commons Attribution License (CC BY). The use, distribution or reproduction in other forums is permitted, provided the original author(s) and the copyright owner(s) are credited and that the original publication in this journal is cited, in accordance with accepted academic practice. No use, distribution or reproduction is permitted which does not comply with these terms. 